\title{
Optimum Solidity on Downwind Thai Sail Windmill
}

\section{Teerawat Klabklay* and Wikanda Sridech}

Combustion Technology and Alternative Energy Research Center, Department of Power Engineering Technology, College of Industrial Technology, King Mongkut's University of Technology North Bangkok, Bangkok 10800, Thailand

\section{("Corresponding author’s e-mail: teerawat.k@cit.kmutnb.ac.th)}

Received: 23 June 2020, Revised: 19 May 2021, Accepted: 23 May 2021

\begin{abstract}
Solidity was a significant parameter affecting the efficiency of wind turbines. It is defined as the ratio between the projected area of all blades and the swept area of the rotor. The solidity could be improved by modifying the shape, cord length, or the number of blades. Research studies mentioned that higher solidity seemed to provide more power due to more blade area. However, it can be argued that if the solidity was too high, it would cause the airflow to be more obstructed and disrupted, causing the gained power to drop down instead. Thus, the optimum solidity, which made the wind turbines maximum effective, must be existent in itself and must be in the range between $0-100 \%$. Thai sail windmill is a kind of horizontal axis wind turbine currently used to pump seawater in salt farms in Thailand, where the general solidity is in the quite wide range of about $15-60 \%$. Mostly, the Thai sail windmill was designed by a rule of thumb. Hence, it has quite a low efficiency, which is only about $10 \%$. This study aims to investigate the optimum solidity of Thai sail windmill in the downwind type to enhance efficiency. The 4blade and 6-blade rotors of 1-m radii were used as the prototypes for experiments using the tow testing method. The results showed that the optimum solidity of 4-blade and 6-blade rotors was $28 \%$, respectively, whereby the maximum efficiency of the 2 rotors was 17 and $25 \%$.
\end{abstract}

Keywords: Thai sail windmill, Downwind rotor, Optimum solidity, Efficiency, Small-scale rotor

Table 1 Nomenclature used in this paper.

\begin{tabular}{ccc}
\hline Parameters & Meaning & Unit \\
\hline$\beta$ & Tip pitch angles & degree \\
$\lambda$ & Tip speed ratio & $\mathrm{N} / \mathrm{A}$ \\
$\omega$ & Angular velocity of the rotor & $\mathrm{kg} / \mathrm{m}^{3}$ \\
$\rho$ & Density of air & $\mathrm{N} / \mathrm{A}$ \\
$\mathrm{A}$ & Solidity & $\mathrm{m}{ }^{2}$ \\
$\mathrm{C}_{\mathrm{p}}$ & Rotor swept area & $\mathrm{N} / \mathrm{A}$ \\
$\mathrm{F}_{1}$ & Power coefficient & $\mathrm{N}$ \\
$\mathrm{F}_{2}$ & Forces acting on the tension springs at $\mathrm{F}_{1}$ side & $\mathrm{N}$ \\
$\mathrm{N}$ & Forces acting on the tension springs at $\mathrm{F}_{2}$ side & $\mathrm{RPM}$
\end{tabular}




\begin{tabular}{ccc}
\hline Parameters & Meaning & Unit \\
\hline$P_{\mathrm{t}}$ & Wind turbine power & $\mathrm{W}$ \\
$\mathrm{P}_{\mathrm{w}}$ & Wind power & $\mathrm{W}$ \\
$\mathrm{R}$ & Radius of the blade tip & $\mathrm{m}$ \\
$\mathrm{R}_{\mathrm{p}}$ & Radius of the pulley & $\mathrm{m}$ \\
$\mathrm{T}$ & Shaft torque & $\mathrm{N} . \mathrm{m}$ \\
$\mathrm{U}$ & Wind velocity & $\mathrm{m} / \mathrm{s}$ \\
$\mathrm{CTSW}$ & Conventional Thai Sail Windmill & $\mathrm{N} / \mathrm{A}$ \\
DTSW & Downwind Thai Sail Windmill & $\mathrm{N} / \mathrm{A}$ \\
$\mathrm{k}-\omega \mathrm{SST}$ & Turbulence model & $\mathrm{N} / \mathrm{A}$ \\
\hline
\end{tabular}

\section{Introduction}

The efficiency of wind turbines depends on various parameters such as airfoil shape, pitch angle, rotor speed, solidity, etc. However, this study focused only on the effect of solidity. Solidity is defined as the ratio between the projected area of all blades and the swept area of the rotor (rotor area). Consequently, the solidity of wind turbines could be calculated from the blade size such as chord length, and the number of blades $[1,2]$. In common sense, the solidity of $0 \%$ could not generate mechanical power from the wind energy because there is no any wind turbine blade. Thus, the wind turbine efficiency would be 0 . On the other hand, the solidity of $100 \%$ would cause the airflow to be completely and severely obstructed until it generates a high-pressure that can drag in the horizontal axis direction, which is called "thrust". It means that it has $100 \%$ of thrust and $0 \%$ of torque. Thus, the wind turbine efficiency would also be 0 . Therefore, the optimum solidity for any types of wind turbines must be existent in itself and must be in the range between $0-100 \%$. Currently, the Thai sail windmill is a kind of the horizontal axis wind turbines which is a lift type. Thai sail windmill is used for pumping the seawater into the salt farms [3] as shown in this article (Figure 1(a)) mostly used in the Samut Songkhram province in Thailand. Generally, the rotor of a conventional Thai sail windmill (CTSW) is in the upwind position and the solidity is in the quite wide range of $15-60 \%$ [4]. Mostly, the efficiency of CTSW is quite low, with an average efficiency of only about $10 \%[4]$.

(a) Conventional Thai sail windmill

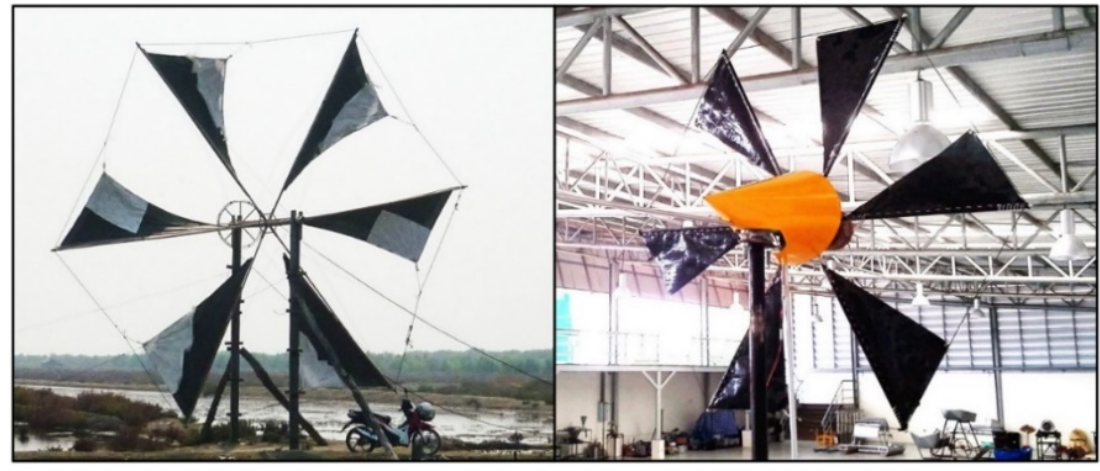

Figure 1 Configuration of Thai sail windmill: CTSW with the upwind type rotor (a) and DTSW with the downwind type rotor (b). 
The objective of this study is to investigate the optimum solidity of the DTSW to enhance efficiency. The downwind type rotor (Figure 1(b)) is used in this study due to its outstanding advantage. This type of rotor could employ as a passive yaw control when the wind direction was changed $[5,6]$. The downwind type rotor would have the rotor placed behind the wind turbine post or tower [7]. For the experiments, the small-scale rotor of DTSW in 2 styles, namely 4-blade and 6-blade rotor, were used as the prototypes for testing. The wind turbine testing can be performed by 3 methods as follows: (i) wind tunnel testing method, (ii) tow testing method, and (iii) field testing method [7]. Generally, wind tunnel testing is the most credible method because it is easy and effective to control the testing conditions, such as setting the uniform inlet velocity, installing measurement accessories, etc. However, due to the limit of available equipment and tools, the tow testing method is most suitable for this research which is the same method as the research of Song [8] and Maughmer [9].

\section{Materials and methods}

\section{Blade configuration}

The CTSW is typically presented with an average rotor size of about $8.0 \mathrm{~m} \mathrm{[3].} \mathrm{The} \mathrm{rotor} \mathrm{plane} \mathrm{is}$ placed in the upwind position wind velocity obtained only in the 2 main directions of the monsoon of Thailand: Northeast and Southwest monsoon. Thus, the CTSW cannot be yawed to another wind direction that might occur. The blades are triangular in shape made of canvas with solidity appearing in the range of about $15-60 \%$ and the tip pitch angle of blades is about $20^{\circ}$ [4]. For this study, the prototypes were built similarly to the CTSW, but the rotor size was scaled down from 8.0 to $1.0 \mathrm{~m}$ for more practical testing. In addition, the prototypes improved the rotor position from the upwind position into the downwind position, which is called "Downwind Thai Sail Windmill" (DTSW) (Figure 1(b)). The downwind rotor can facilitate the wind turbine rotor to have the passive yaw control when the wind direction is changed $[5,6]$, to augment the opportunity in the energy capture. Three levels of solidity were selected randomly consisting of 22, 28 and $34 \%$ to investigate the optimum solidity and to enhance the wind turbine efficiency. The solidity range of CTSW is most commonly found from a survey in Samut Songkhram province. The triangular shape of the 4-blade and 6-blade rotors was designed on the cord size throughout span radius according to the 3 levels of solidity (Figure 2). Therefore, the prototypes for 3 levels of solidity were built according to the design (Figures 3 - 5). Pitch angle is an important parameter that highly impacted the wind turbine efficiency because it affected the angle of attack on the wind turbine blades, which directly influenced the lift to drag ratio [10]. The blade pitch angles of DTSW were not constant along the span radius because the blades have an automatic twisting. However, the blade pitch angles of the prototypes were set by only the tip pitch angles (Figure 6) [11]. For this study, the tip pitch angles were selected randomly by 4 angles as follows: $5,10,15$ and $20^{\circ}$ to find the optimum tip pitch angle. 
(a) Solidity $=22 \%\left(\sigma_{22 \%}\right)$

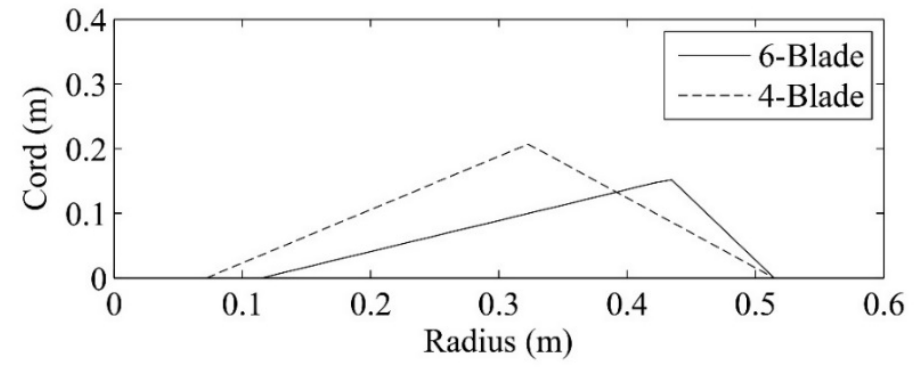

(b) Solidity $=28 \%\left(\sigma_{28 \%}\right)$

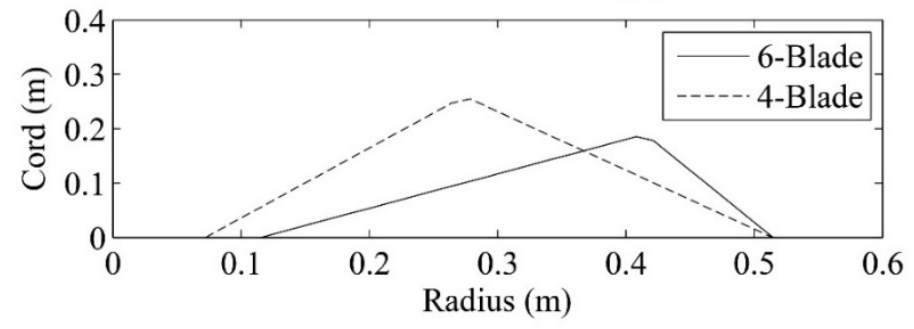

(c) Solidity $=34 \%\left(\sigma_{34 \%}\right)$

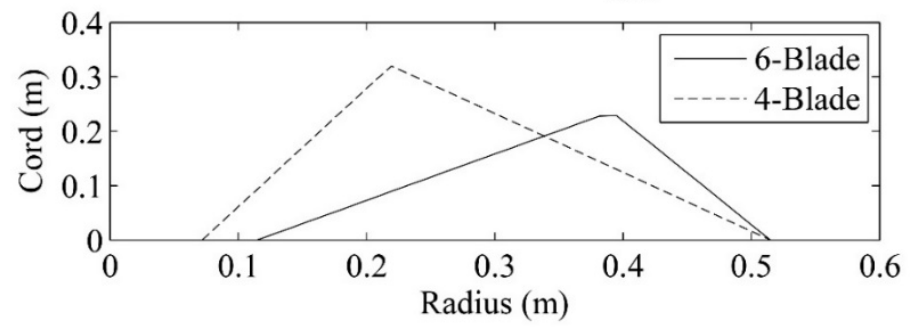

Figure 2 The blade shape and size of the 4-blade and 6-blade rotor of the prototypes: 22 (a), 28 (b) and $34 \%$ (c) of solidity.

(a) 4-blade $\sigma_{22} \%$

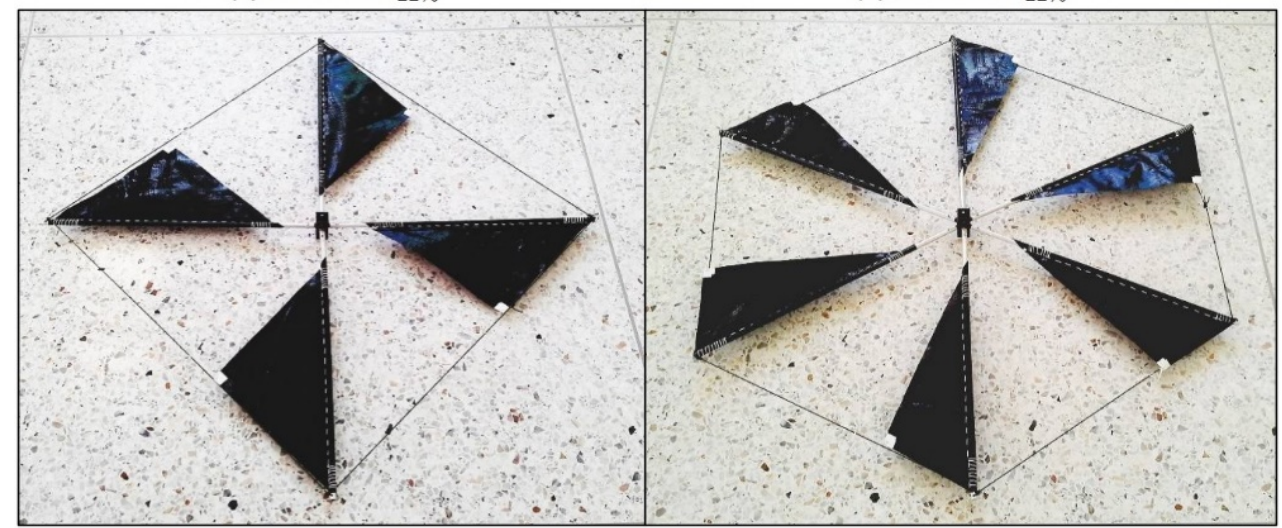

Figure 3 DTSW prototypes with the solidity of $22 \%$ : 4-blade rotor (a) and 6-blade rotor (b). 
(a) 4-blade $\sigma_{28 \%}$

(b) 6-blade $\sigma_{28 \%}$

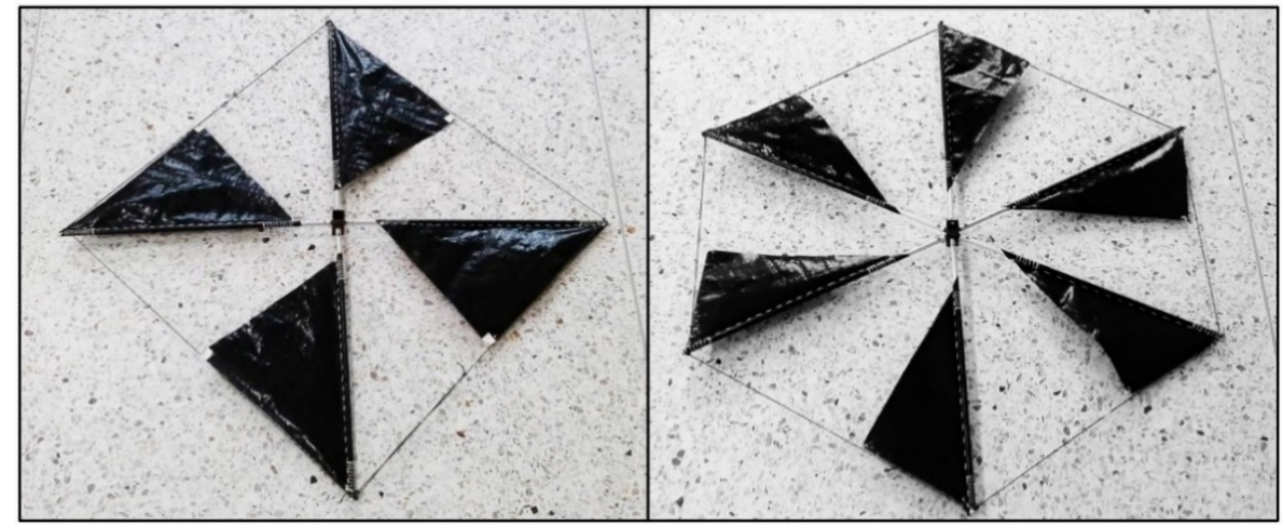

Figure 4 DTSW prototypes with the solidity of $28 \%$ : 4-blade rotor (a) and 6-blade rotor (b).

(a) 4-blade $\sigma_{34 \%}$

(b) 6-blade $\sigma_{34 \%}$

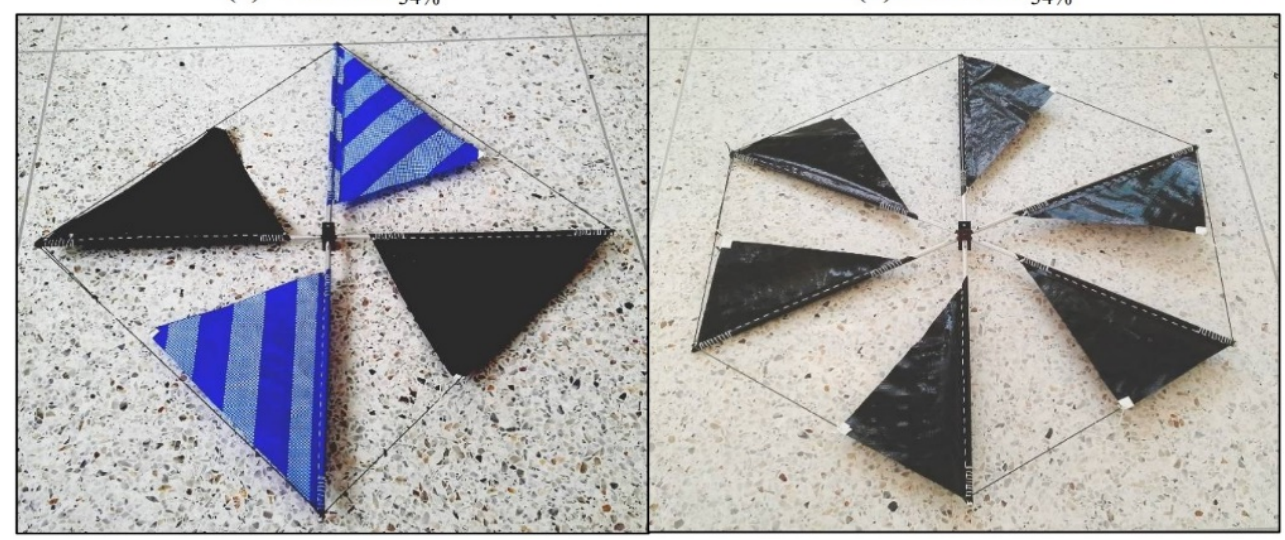

Figure 5 DTSW prototypes with the solidity of $34 \%$ : 4-blade rotor (a) and 6-blade rotor (b).

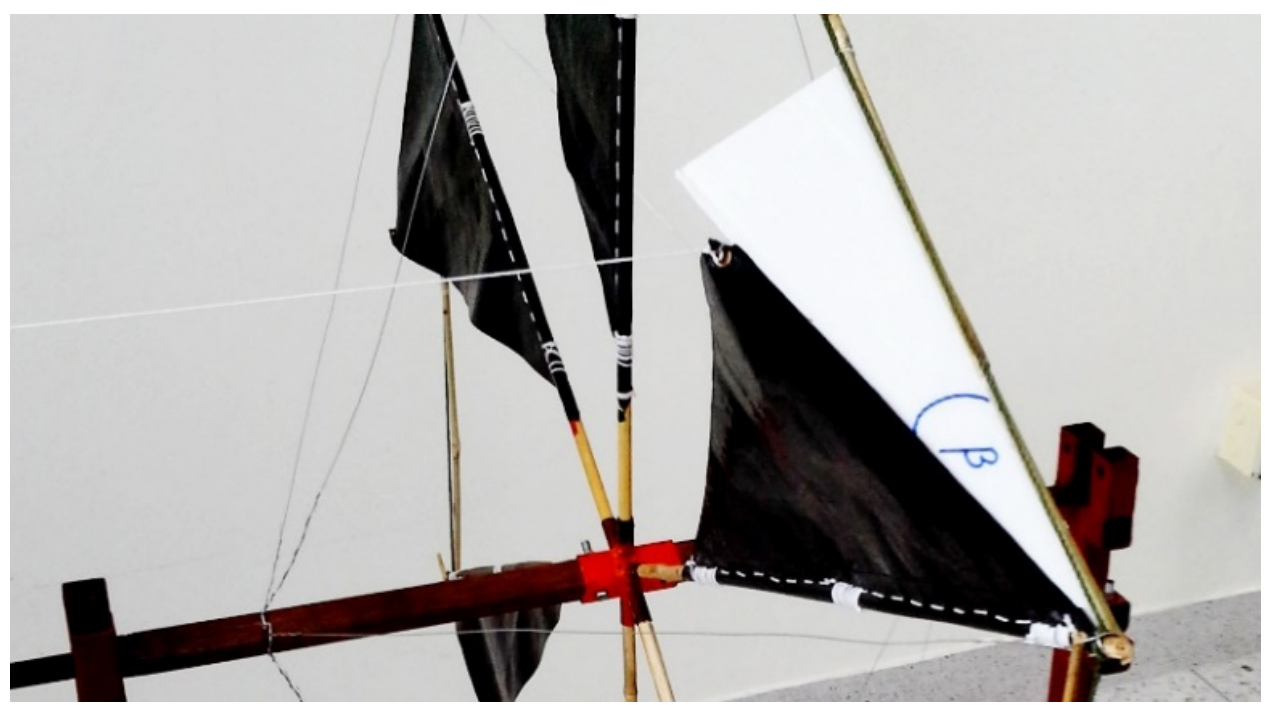

Figure 6 Tip pitch angles $(\beta)$. 


\section{Testing procedure}

Tow testing is an effective technique widely used globally for testing a wind turbine [7,11]. This method was implemented because of the limited availability of equipment and tools. The tow testing method is used to move the prototype forward into the stationary air with a constant speed by moving the towing vehicle $[8,9]$ whereby the interference from the local wind must not be higher than $5 \%$ of the tested speed. It should be noted that the vehicle speed has the same meaning as the inlet wind velocity for testing in the wind tunnel, while the prototype is stationary at all times. For this study, the carbon steel structure was installed on a pick-up truck to facilitate fastening the prototypes and all measurement accessories such as anemometer, tension spring, and optical rotational speed sensor. The rotor was installed $2.5 \mathrm{~m}$ away from the vehicle's roof to avoid turbulent disturbance from the boundary layer effect [12]. The anemometer was mounted in front of the rotor plane about $1.0 \mathrm{~m}$ [11]. The tested speed for this study was $5.6 \mathrm{~m} / \mathrm{s}$ because it was corresponding to an average wind velocity according to the local weather of the working area.

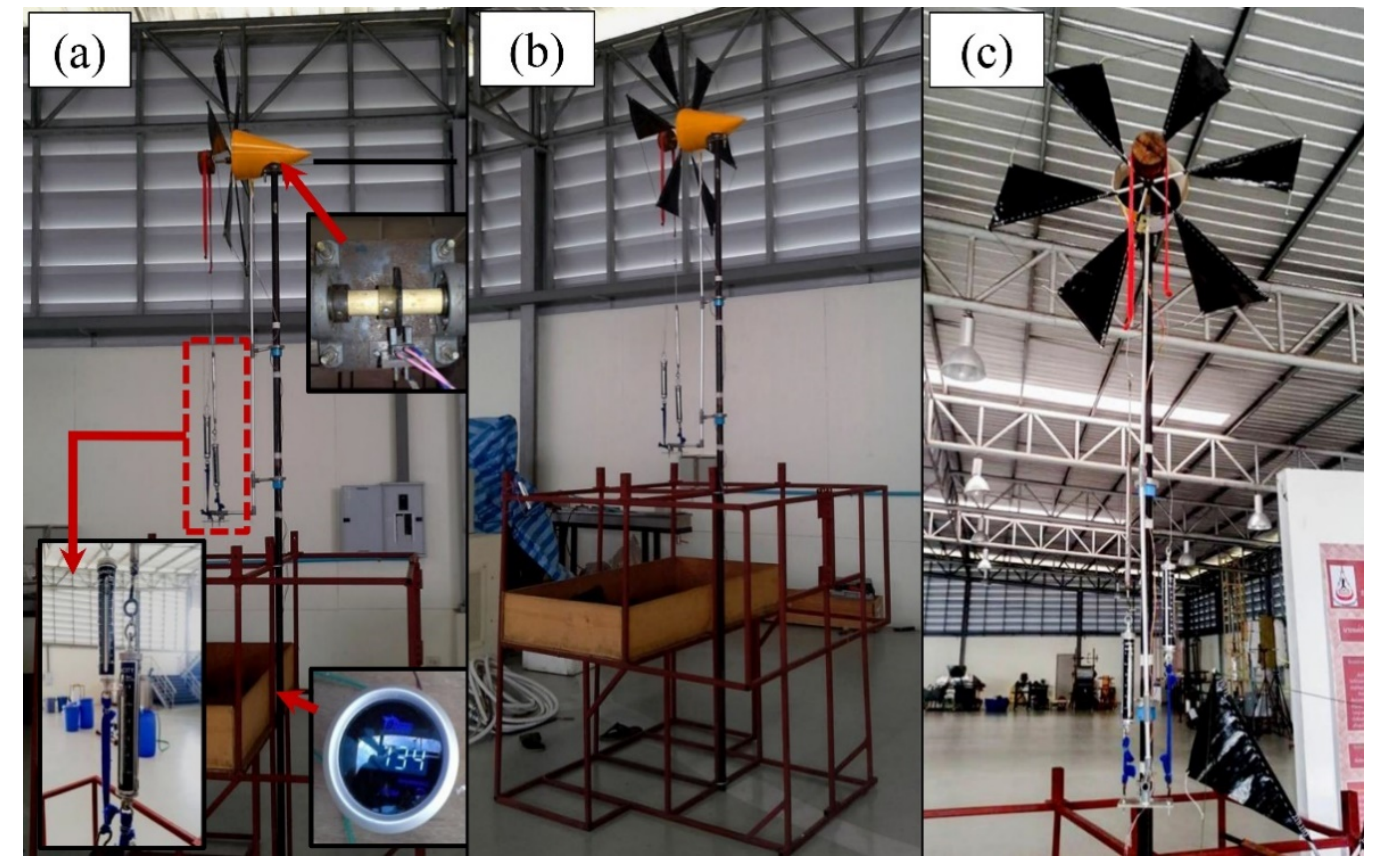

Figure 7 The prototype and all measurement accessories installation: Tension spring and optical speed sensor (a), carbon steel structure and anemometer (b) and pulley and turnbuckle (c).

The testing procedure could be briefly explained as follows:

1) Install the carbon steel structure, prototype, and all measurement accessories on a pick-up truck (Figure 7).

2) Monitor the local wind interference; whereby the pick-up truck should start moving only if the local wind does not exceed $5 \%$ of the tested speed.

3) Drive the pick-up truck forward with a constant speed on the route, which must be straight and not sloping (Figure 8).

4) Put the resistance load on the rotor shaft by adjusting the turnbuckle screw to measure the torque and the rotor speed happening.

5) Measure the F1 and F2 by tension springs and measure the rotor speed by optical rotating speed sensor when the system is already in a steady-state.

6) Put more resistance load and measure the F1, F2 and the rotor speed again according to the previous step until the rotor speed stops rotating. 


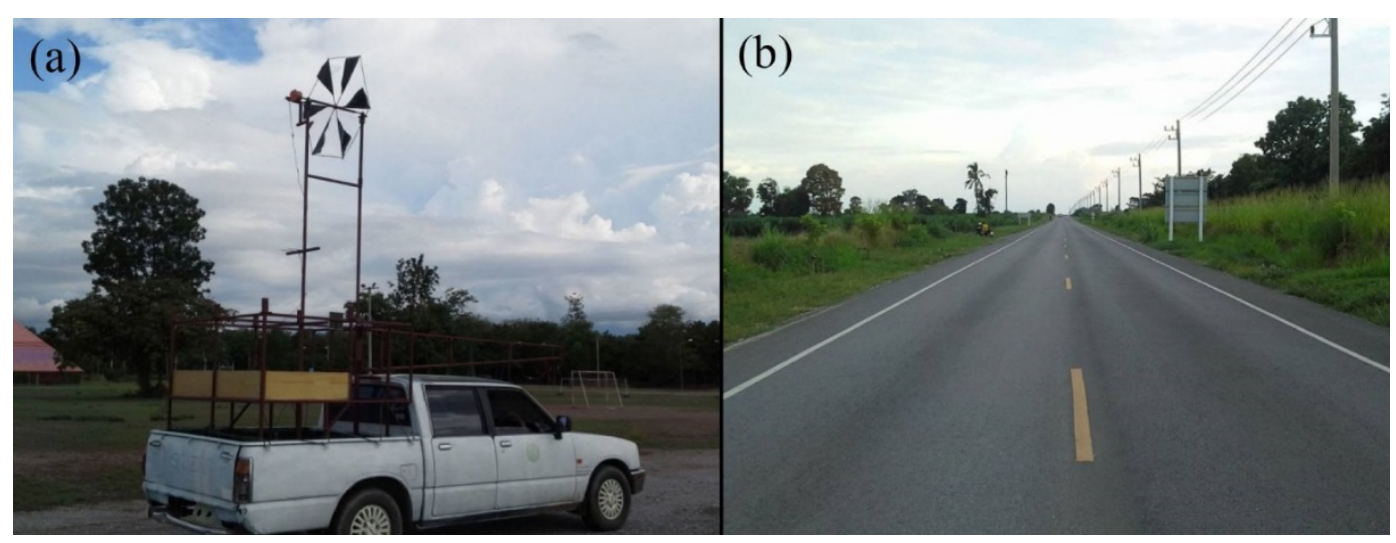

Figure 8 Tow testing: Carbon steel structure on a pick-up truck (a) and Straight route for testing (b).

\section{Wind turbine efficiency}

Power coefficient $\left(\mathrm{C}_{\mathrm{p}}\right)$ is a wind turbine characteristic indicating how much the wind turbine was effective [13]. Wind turbine efficiency is the power coefficient multiplied by $100 \%\left(\mathrm{C}_{\mathrm{p}} \times 100 \%\right)$. The power coefficient is the ratio between the gained power from the wind turbine $\left(\mathrm{P}_{t}\right)$ and the wind power $\left(\mathrm{P}_{\mathrm{w}}\right)$ as shown in the Eq. (1):

$$
\mathrm{C}_{\mathrm{p}}=\frac{\mathrm{P}_{\mathrm{t}}}{\mathrm{P}_{\mathrm{w}}}=\frac{\mathrm{T} \cdot \omega}{0.5 \rho \mathrm{AU}}
$$

where $\mathrm{T}$ represents the shaft torque $(\mathrm{N} \cdot \mathrm{m})$, which is generated by the aerodynamic load of the wind turbine blades, $\omega$ is the angular velocity of the rotor $(\mathrm{rad} / \mathrm{s})$, which can be calculated by Eq. (2):

$$
\omega=2 \pi \mathrm{N} / 60
$$

where $\mathrm{N}$ represents the rotor speed in the unit of revolution per minute (RPM), $\rho$ is the density of air $\left(\mathrm{kg} / \mathrm{m}^{3}\right)$. A is the rotor swept area $\left(\mathrm{m}^{2}\right)$. U is the wind velocity $(\mathrm{m} / \mathrm{s})$. According to the free body diagram of the torque acting on the pulley of the prototype (Figure 9), the shaft torque could be measured using the equilibrium of forces and torques, which is the basic principle of mechanics (Newton's $1^{\text {st }}$ law of motion) [11]. When the system is in equilibrium, the sum of all forces and the sum of all torques acting on the system must be 0 . Hence, the shaft torque can be shown in Eq. (3):

$$
\mathrm{T}=\mathrm{R}_{\mathrm{p}}\left(\mathrm{F}_{2}-\mathrm{F}_{1}\right)
$$

where $R_{p}$ is the radius of the pulley, F1 and F2 are the forces acting on the tension springs as shown in the free body diagram. Tip speed ratio $(\lambda)$ is the ratio between the tangent velocity at the blade tip and the wind velocity [13], which is presented in Eq. (4):

$\lambda=\omega \mathrm{R} / \mathrm{U}$

where $\mathrm{R}$ represents the radius of the blade tip, it should be noted that both the power coefficient and tip speed ratio would be dimensionless. 

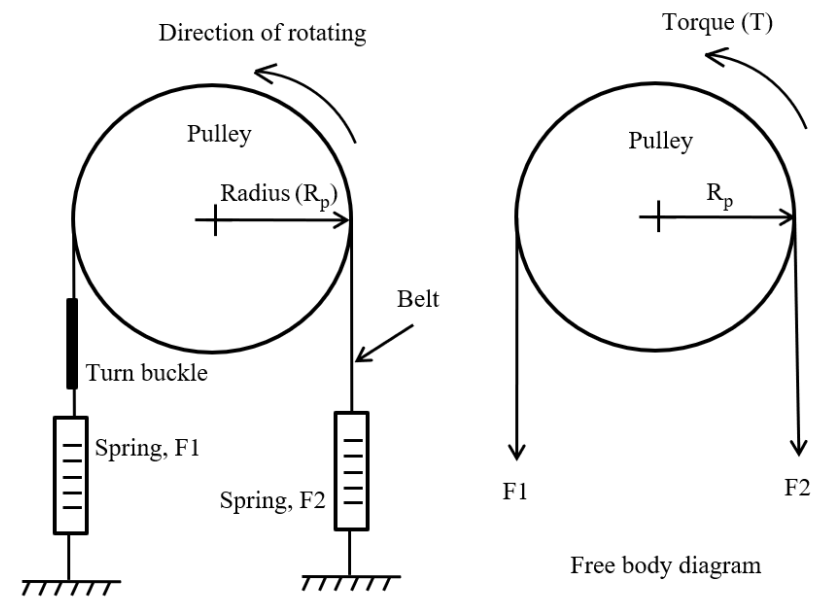

Figure 9 Free body diagram of the torque acting on the pulley.

\section{Results and discussion}

All the prototypes were tested by the tow testing method, which employed a pick-up truck to move with a constant speed of $5.6 \mathrm{~m} / \mathrm{s}$. The prototypes used the 4 levels of the tip pitch angle, namely $5,10,15$ and $20^{\circ}$ for experiments; which is the same as the previous research [11] that focused on the effect of the size of tip pitch angle on the efficiency and annual energy production of DTSW. For the general results of this article, according to Figures 10 and 11, the results showed that the left side of all graphs of the power coefficient has no measurement data points because the rotor stopped rotating immediately after the final resistant load was added pulley. The final resistant load was enough for the rotor to speed rapidly, slow, and become 0 instantaneously. At very low speeds of the rotor, the angle of attack throughout the span radius of blades would be high that the lift force, which is the origin of the torque and thrust, decreased strongly and rapidly. This is called "stall phenomenon" [14,15]. This is why the wind turbine rotor stopped rotating immediately and it could not measure the power coefficient at very low speeds. A similar result was reported by Chen et at. [16].

According to the experimental results of the 4-blade rotor of the DTSW (Figure 10), the results are the effect of 3 levels of solidity, namely 22, 28 and $34 \%$ including the effect of 4 levels of the tip pitch angle, namely $5,10,15$ and $20^{\circ}$ on the efficiency of DTSW. Firstly, the results showed that the solidity of $34 \%$ provided the lowest optimal tip speed ratio, which was only about 1.2 because the rotor speed was quite slow. This is caused by the obstruction from the large area of blades. On the other hand, the solidity of $28 \%$ provided the highest optimal tip speed ratio, which was about $1.8-2.0$, at the same tested wind velocity. The difference of the optimal tip speed ratio is the difference in wind turbine characteristic implying how much the rotor speed should operate to get maximum efficiency. Secondly, it was apparent that the solidity of $22 \%$ provided the lowest efficiency for every tip pitch angle because of the too low area of wind turbine blades for generating torque. Lastly, the optimum solidity was $28 \%$ and the optimum tip pitch angle was about $5-10^{\circ}$, which provided the highest efficiency of about $17 \%$. The effect of these 4 levels of the tip pitch angle on the efficiency of 4-blade rotor of DTSW confirmed the results reported in the previous research [11]. However, it should be noted that the solidity of $34 \%$ together with the tip pitch angle of 5, 10 and $15^{\circ}$ provided high efficiency, especially at the low tip speed ratio, which provided the maximum efficiency of about $15-16 \%$. 

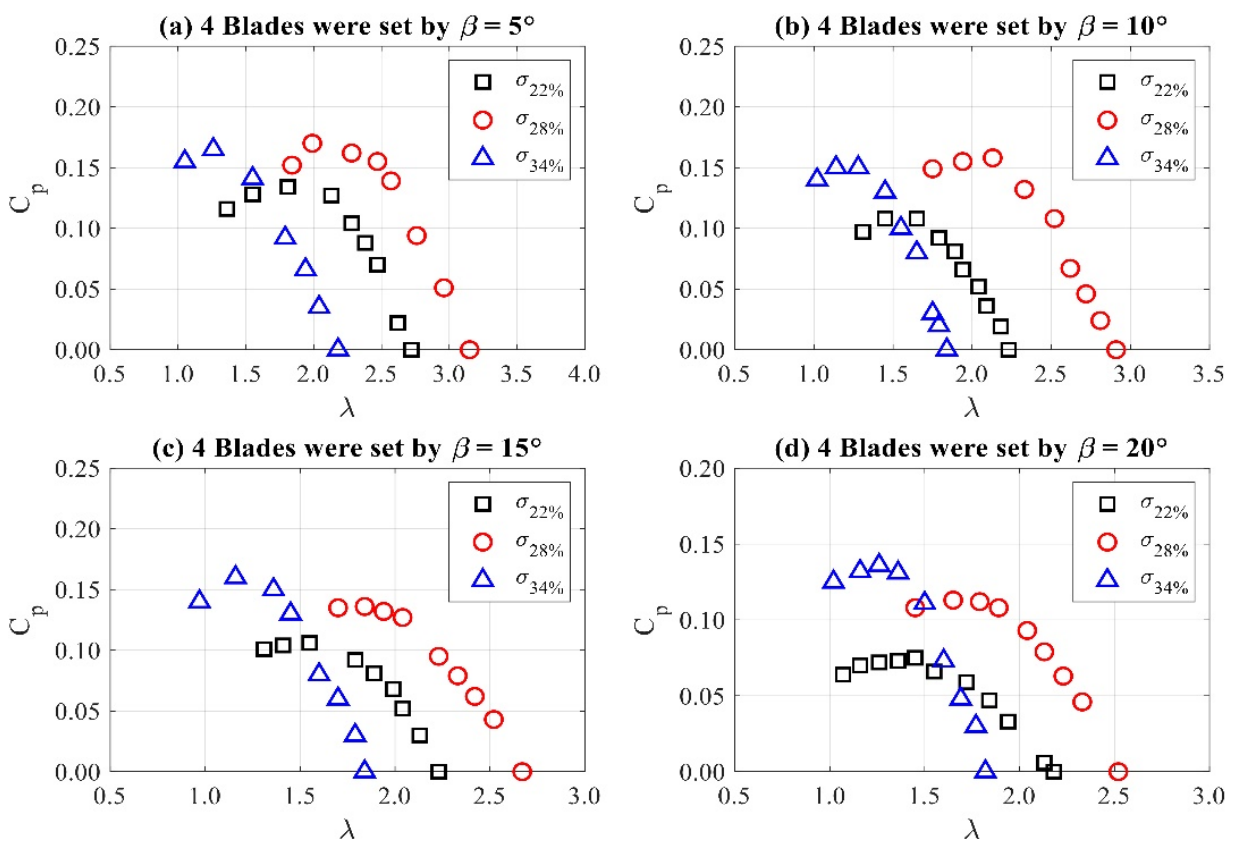

Figure 10 The solidity effect of the power coefficient of the 4-blade DTSW.

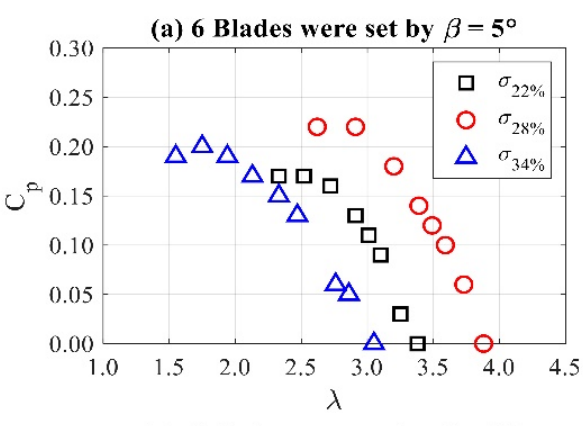

(c) 6 Blades were set by $\beta=15^{\circ}$

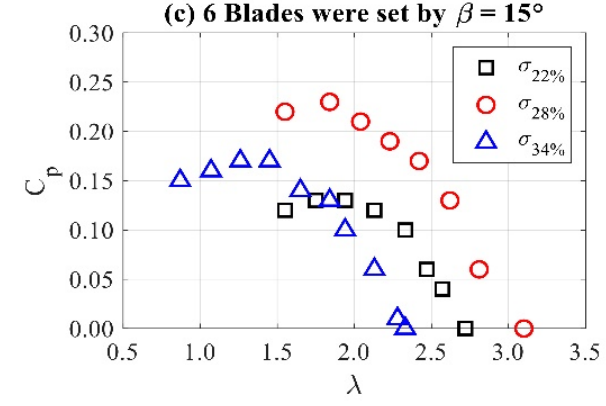

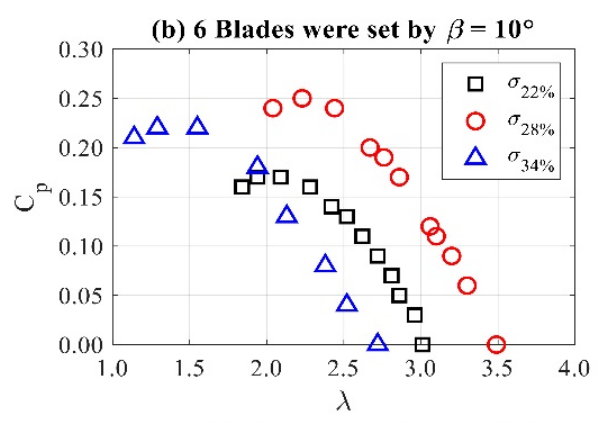

(d) 6 Blades were set by $\beta=20^{\circ}$

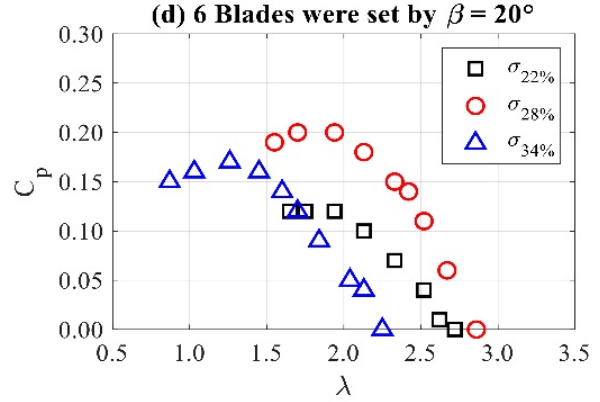

Figure 11 The solidity effect of the power coefficient of the 6-blade DTSW.

According to the experimental results of the 6-blade rotor of the DTSW (Figure 11), it showed that the solidity of $34 \%$ provided the lowest optimal tip speed ratio, which was only about $1.2-1.7$. On the other hand, the solidity of $28 \%$ provided the highest optimal tip speed ratio, which was about $1.8-2.7$, at the same tested wind velocity. Both were higher than the 4-blade rotor style. Secondly, the solidity of 22 $\%$ provided the lowest efficiency for all tip pitch angles compared with the other levels of solidity. Thirdly, it was obvious that the smaller tip pitch angle influenced the prototype to have a more tip speed ratio. Similar results were reported by Asl and Yoon [17] and Bottasso et at. [18]. Lastly, the optimum solidity was $28 \%$ and the optimum tip pitch angle was about $5-10^{\circ}$; which provided the highest 
efficiency of about $25 \%$. The effect of these 4 levels of the tip pitch angle on the efficiency of 6-blade rotor of DTSW is the same results that reported in the previous research [11]. However, it should be noted that the solidity of $34 \%$ together with the tip pitch angle of 5 and $10^{\circ}$ provided highly efficient, especially at the low tip speed ratio, which provided the maximum efficiency of about $20-22 \%$. It was apparent that the 6-blade rotor would provide maximum efficiency more than the 4-blade rotor of about 8 $\%$.

The CFD simulation by means of 3D RANS and the turbulence model of $k-\omega$ SST was carried on approximately to analyze the thrust of 4-blade and 6-blade rotors of DTSW. The simulation was performed only in the conditions of each prototype's maximum efficiency, which were at the tip pitch angle of $10^{\circ}$ and each prototype's optimal tip speed ratio. The results showed that the bigger solidity caused the DTSW to generate more thrust. The 4-blade and 6-blade rotors with the solidity of 22, 28 and $34 \%$ produced the thrust that was equal to $17.58,23.11,30.85$ and $13.44,20.98,26.23 \mathrm{~N}$, respectively. These thrusts are caused by lift and drag occurring on each blade including the total pressure difference between the front and rear of the rotor as shown in the pressure difference contour in Figures 12(a) 17(a). Normally, the thrust is an unpleasant force for the wind turbine because it directly affects the wind turbine structure.
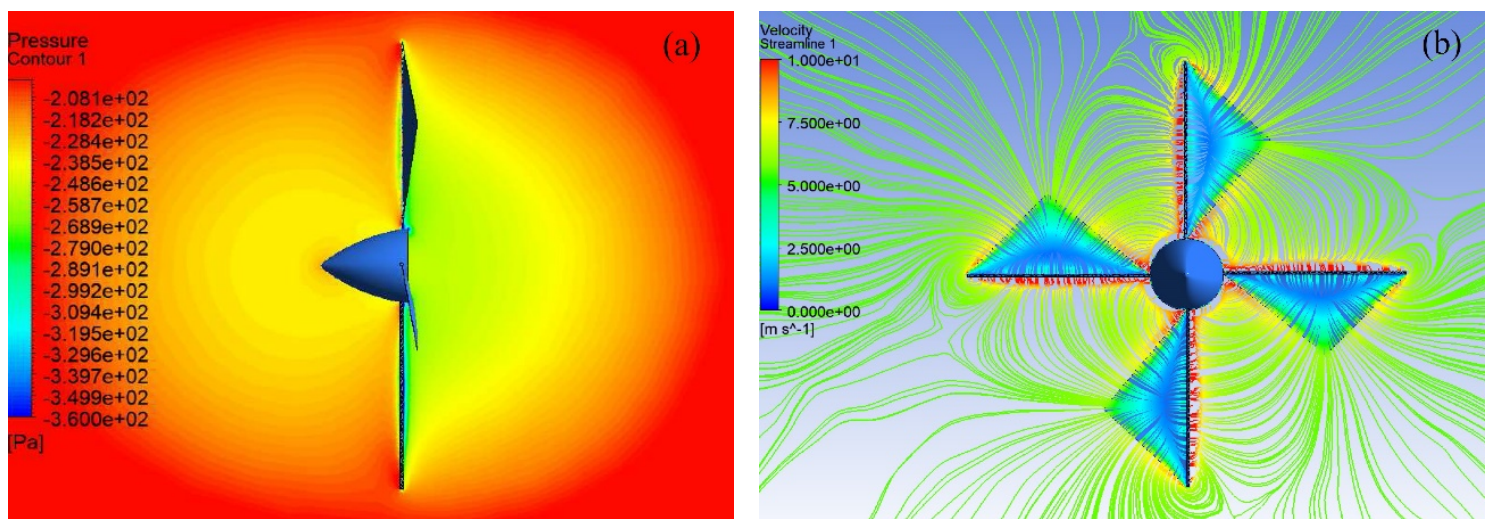

Figure 12 Surface plots of the 4-blade rotor of $22 \%$ solidity: Pressure contour (a) and streamline (b).
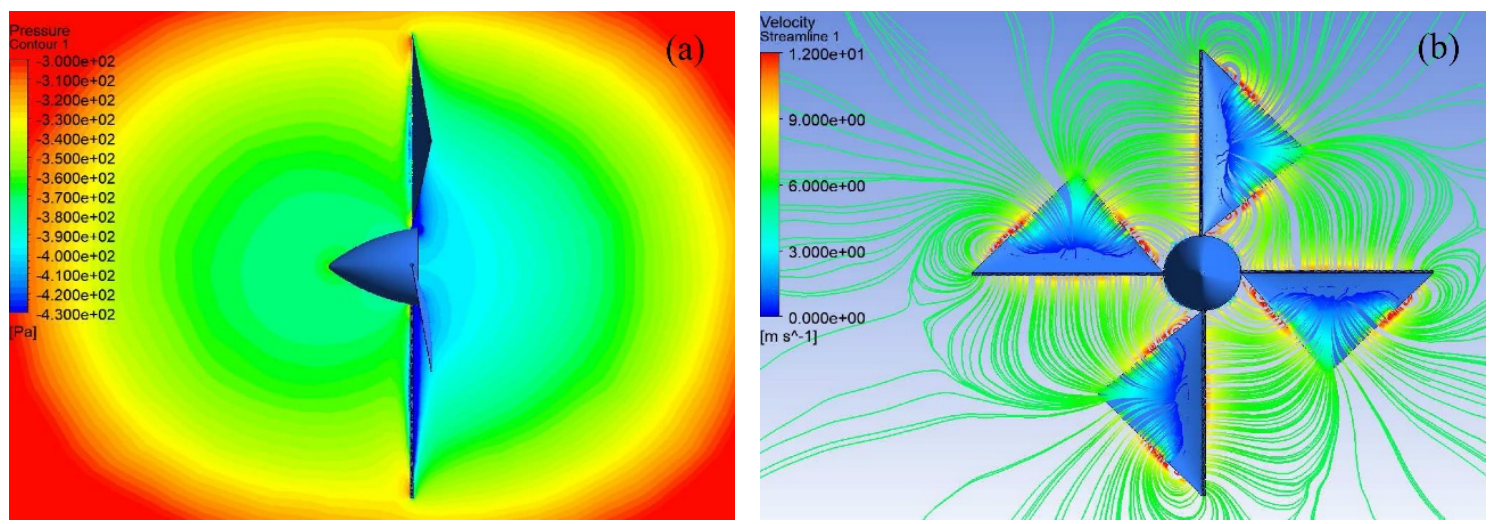

Figure 13 Surface plots of the 4-blade rotor of $28 \%$ solidity: Pressure contour (a) and streamline (b). 

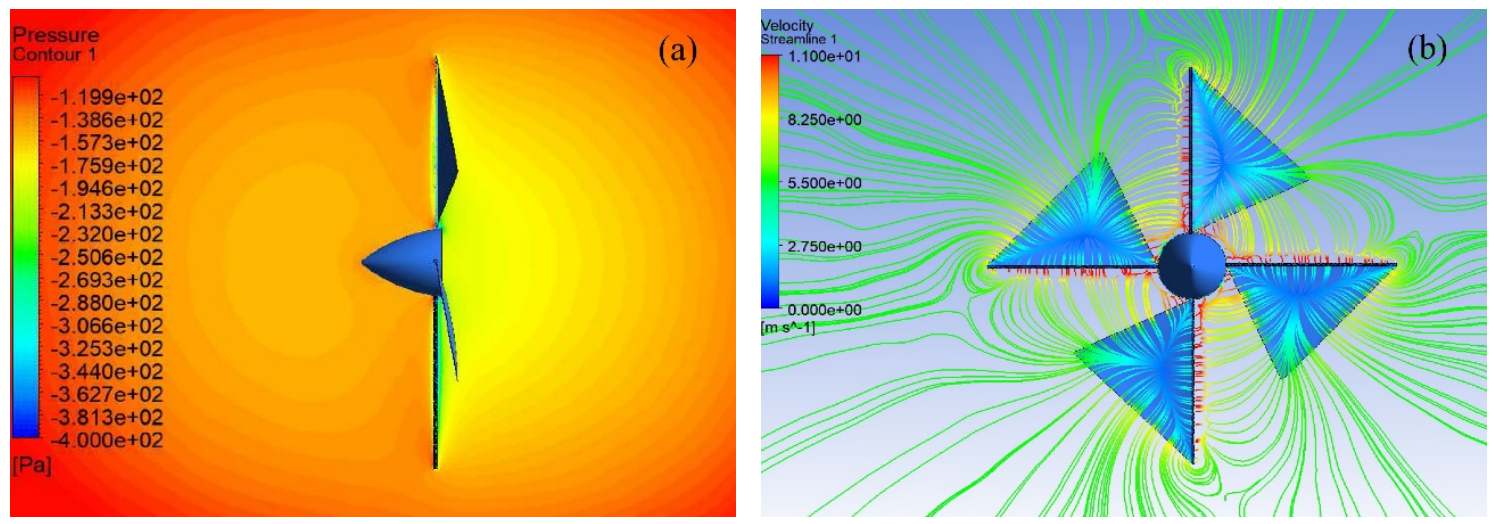

Figure 14 Surface plots of the 4-blade rotor of $34 \%$ solidity: Pressure contour (a) and streamline (b).
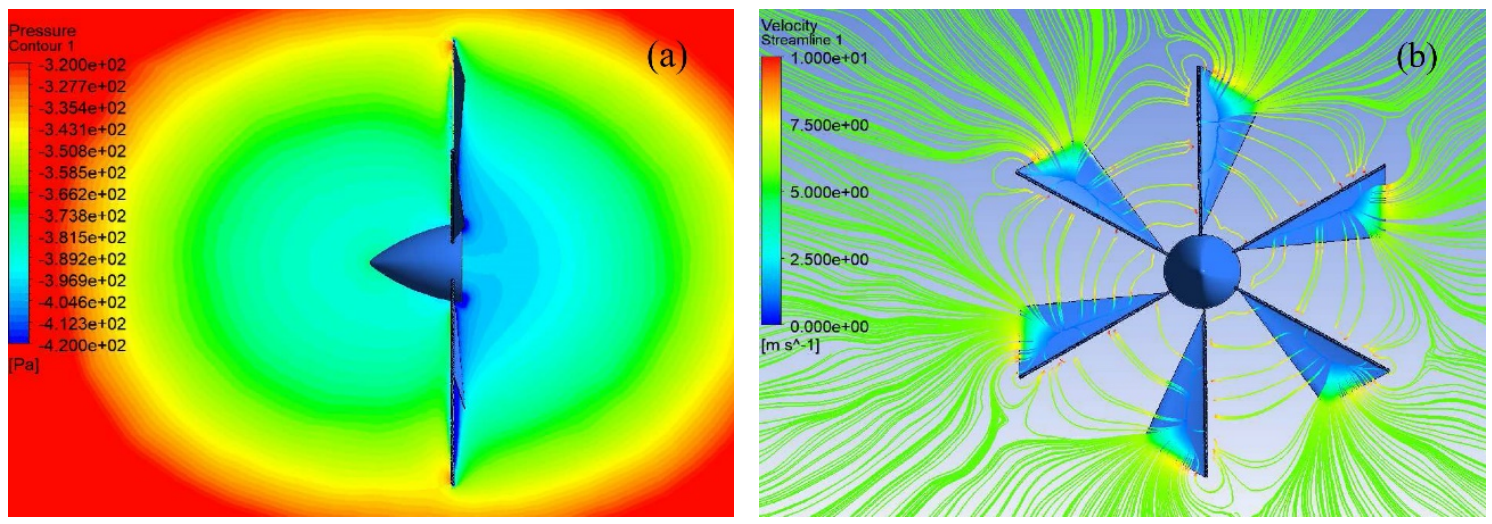

Figure 15 Surface plots of the 6-blade rotor of $22 \%$ solidity: Pressure contour (a) and streamline (b).
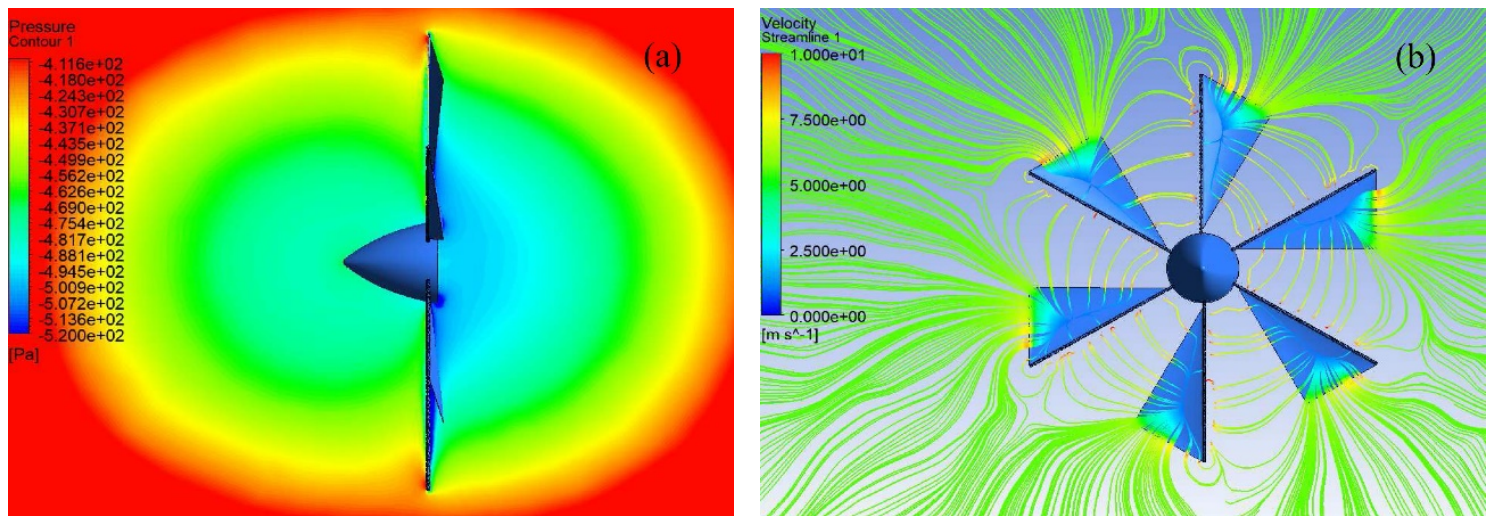

Figure 16 Surface plots of the 6-blade rotor of $28 \%$ solidity: Pressure contour (a) and streamline (b). 

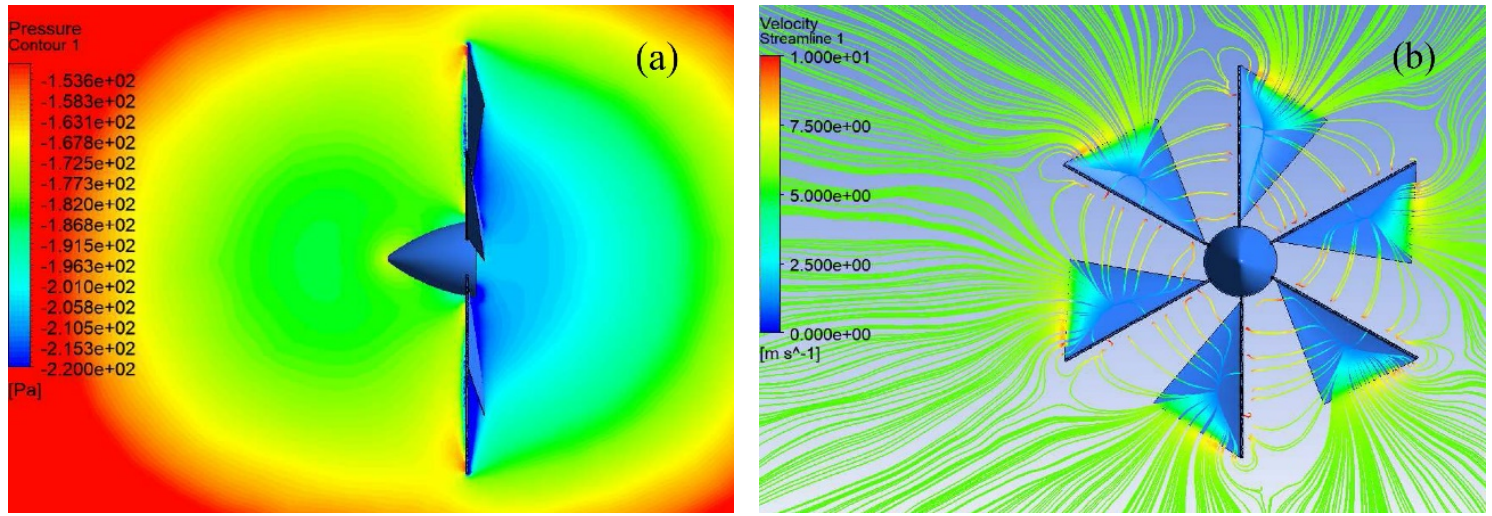

Figure 17 Surface plots of the 6-blade rotor of $34 \%$ solidity: Pressure contour (a) and streamline (b).

For the solidity analysis of DTSW, although the solidity of $34 \%$ has more area of the blade to generate torque, a part of aerodynamic force can become lost to the thrust due to a total pressure difference and more lift and drag from a more blade area. On the other hand, although the solidity of 22 $\%$ can produce the lowest thrust and total pressure difference, the blade area is too small to generate higher torque. Thus, the solidity of $28 \%$ might be the most balanced between the torque and thrust generated on 4-blade and 6-blade rotor of DTSW. This was the reason why the optimum solidity of DTSW was equal to $28 \%$ approximately. Furthermore, it can be seen that the 4-blade rotor appeared the tip loss more than the 6-blade rotor. It can be observed from the vortices' size at each blade's tip as shown in the velocity streamline plot in Figures 12(b) - 17(b). Finally, the 4-blade rotor had the thrust and the total pressure difference more than the 6-blade rotor as shown in Figures 12(a) - 17(a). This was the reason why the efficiency of the 4-blade rotor was lower than the 6-blade rotor.

\section{Conclusions}

For the 4-blade DTSW, the optimum solidity was $28 \%$ and the optimum tip pitch angle was about 5 $-10^{\circ}$, which provided the highest efficiency of about $17 \%$. For the 6-blade DTSW, the optimum solidity was $28 \%$ and the optimum tip pitch angle was about $5-10^{\circ}$, which provided the highest efficiency of about $25 \%$. In addition, it was apparent that the 6-blade DTSW provided maximum efficiency of about $8 \%$ more than the 4-blade DTSW. The suggestion for the future research may be the experiments on a new shape of blade and the high accuracy prediction of DTSW efficiency for all conditions by computational fluid dynamics.

\section{Acknowledgements}

The authors acknowledge the financial support from the King Mongkut's University of Technology North Bangkok, Bangkok, Thailand and Suranaree University of Technology, Nakhon Ratchasima, Thailand.

\section{References}

[1] KA Fagbenro, MA Mohamed and DH Wood. Computational modeling of the aerodynamics of windmill blades at high solidity. Energy Sustain. Dev. 2014; 22, 13-20.

[2] V Bhargava and CK Rao. Effect of rotor solidity on the tip losses from wind turbine rotor blades. Int. J. Eng. Res. 2016; 5, 803-6.

[3] P Mukhia. 1981, Performance and aerodynamic analysis of the Thai four bladed wooden rotor coupled to a ladder pump. Ph. D. Dissertation. Asian Institute of Technology, Pathum Thani, Thailand.

[4] R Thepwong. 2013, Design improvements of Thai sail windmill for water pumping. Ph. D. Dissertation. Rajamangala University of Technology Rattanakosin, Nakhon Pathom, Thailand.

[5] C Kress, N Chokani and RS Abhari. Downwind wind turbine yaw stability and performance. Renew. Energy 2015; 83, 1157-65.

[6] P Gipe. Wind power. James \& James (Science Publishers), USA, 2004, p. 175-8. 
[7] AD Spera. Wind turbine technology: Fundamental concepts of wind turbine engineering. ASME press, New York, 1998, p. 323-5.

[8] Q Song. 2012, Design, fabrication, and testing of a new small wind turbine blade. Ph. D. Dissertation. The University of Guelpe, Ontario, Canada.

[9] MD Maughmer. 1976, Optimization and characteristics of a sailwing windmill rotor. Ph. D. Dissertation. Princeton University, New Jersey, USA.

[10] C Thumthae and T Chitsomboon. Optimal angle of attack for untwisted blade wind turbine. Renew. Energy 2009; 34, 1279-84.

[11] T Klabklay and T Chitsomboon. Optimum pitch angle of downwind Thai sail windmill for maximum annual energy production. Songklanakarin J. Sci. Tech. 2018; 40, 1473-8.

[12] WH Hucho and G Sovran. Aerodynamics of road vehicles. Annu. Rev. Fluid Mech. 1993; 25, 485537.

[13] JF Manwell, JG Mcgowan and AL Rogers. Wind energy explained. John Wiley \& Son, New Jersey, 2009, p. 63-65.

[14] A Choudhry, M Arjomandi and R Kelso. Methods to control dynamic stall for wind turbine applications. Renew. Energ. 2016; 86, 26-37.

[15] JW Larsen, SRK Nielsen and S Krenk. Dynamic stall model for wind turbine airfoils. J. Fluids Struct. 2007; 23, 959-82.

[16] TY Chen, YT Liao and CC Cheng. Development of small wind turbines for moving vehicles: Effects of flanged diffusers on rotor performance. Exp. Therm. Fluid Sci. 2012; 42, 136-42.

[17] HJ Asl and J Yoon. Power capture optimization of variable-speed wind turbines using an output feedback controller. Renew. Energ. 2016; 86, 517-25.

[18] CL Bottasso, F Campagnolo and V Petrovoc. Wind tunnel testing of scaled wind turbine models: Beyond aerodynamics. J. Wind Eng. Ind. Aerodyn. 2014; 127, 11-28. 